\title{
The association of clinical frailty with outcomes of patients reviewed by rapid response teams: an international prospective observational cohort study
}

Ralph K. L. So ${ }^{1 *} \mathbb{D}$, Jonathan Bannard-Smith², Chris P. Subbe ${ }^{3}$, Daryl A. Jones ${ }^{4}$, Joost van Rosmalen ${ }^{5}$, Geoffrey K. Lighthall ${ }^{6}$ and the METHOD study investigators

\begin{abstract}
Background: Frailty is a state of vulnerability to poor resolution of homeostasis after a stressor event and is strongly associated with adverse outcomes. Therefore, the assessment of frailty may be an essential part of evaluation in any healthcare encounter that might result in an escalation of care. The purpose of the study was to assess the frequency and association of frailty with clinical outcomes in patients subject to rapid response team (RRT) review.
\end{abstract}

Methods: In this multi-national prospective observational cohort study, centres with existing RRTs collected data over a 7-day period, with follow up of all patients at $24 \mathrm{~h}$ following their RRT call and at hospital discharge or 30 days following the event trigger (whichever came sooner). Investigators also collected data on the triggers and interventions provided and a bedside assessment on the level of patients' frailty using a clinical frailty scale.

Results: Amongst 1133 patients, 40\% were screened as frail, which was associated with older age $(p<0.001)$, admission under a medical speciality $(p<0.001)$, increased severity of illness at the time of the RRT review $(p=0.0047)$, and substantially higher frequency of limitations of care $(p<0.001)$. Importantly, $72 \%$ of patients screened as frail were either dead or dependent on hospital care by 30 days $(p<0.001)$. In the multivariable analysis, the significant risk factors for the composite endpoint "poor recovery" (died or were hospital-dependent by 30 days) were age (odds ratio (OR), 1.04; $95 \%$ confidence interval $(\mathrm{Cl}), 1.03-1.05 ; p<0.001)$, frailty level $(p<0.001)$, existing limitation of care $(\mathrm{OR}, 2.0 ; 95 \% \mathrm{Cl}, 1.3-3.0 ; p<0.001)$, and the quick sequential organ failure assessment (qSOFA) score $(p<0.001)$.

Conclusions: Higher frailty scores were associated with increased mortality and dependence on health care at 30 days. Our results indicate that frailty has an influence on the clinical trajectory of deteriorating patients and that such assessment should be included in discussion of goals and expectations of care.

Trial registration: Netherlands Trial Registry, NTR5535. Registered on 23 December 2015.

Keywords: Frailty, Rapid response team, Acute illness, Advanced directives, Outreach team, Medical emergency team

\footnotetext{
* Correspondence: ralphklso@gmail.com

${ }^{1}$ Department of Intensive Care, Albert Schweitzer Hospital, Albert

Schweitzerplaats 25, Dordrecht, the Netherlands

Full list of author information is available at the end of the article
}

(c) The Author(s). 2018 Open Access This article is distributed under the terms of the Creative Commons Attribution 4.0 International License (http://creativecommons.org/licenses/by/4.0/), which permits unrestricted use, distribution, and reproduction in any medium, provided you give appropriate credit to the original author(s) and the source, provide a link to the Creative Commons license, and indicate if changes were made. The Creative Commons Public Domain Dedication waiver (http://creativecommons.org/publicdomain/zero/1.0/) applies to the data made available in this article, unless otherwise stated. 


\section{Background}

Hospitals manage patients with increasingly complex medical needs. Some of the increase in the overall patient acuity can be accounted for by the increase in ambulatory surgery and the substitution of outpatient for inpatient care and some by the outpatient management in medical cases of less seriously ill patients who would previously would have been hospitalised. In this environment recognition of clinically important deterioration is becoming more challenging, diagnostic processes more complex and full recovery to good health more difficult to achieve. Many hospitals worldwide have introduced rapid response teams (RRTs) to identify and respond to patients who are experiencing important clinical deterioration, particularly on the hospital wards.

Response to treatment depends amongst other factors on timely intervention and the reversibility of a condition. Reversibility may be influenced by physiological reserve an entity that is not directly measured - but which diminishes with age and significant comorbidities, and manifests as clinical frailty. Frailty can be measured as the sum of acquired functional deficits and is related to mortality after hospital or intensive care admission and the need for support at home [1-3]. Although the impact of frailty has been assessed in the hospital setting, the impact of frailty has not been described in the context of rapid response systems.

METHOD is an international service evaluation that records and compares outcomes of patients reviewed by RRTs. In a 2014 study, sites collected data during a 7-day period with follow up at $24 \mathrm{~h}$ after each RRT review. Results described 1188 RRT activations from 51 hospitals in 5 countries; $24 \%$ of patients were admitted to the ICU, $10 \%$ died, and 25\% had new limitations in therapy implemented [4]. A limitation of the METHOD 2014 study was the lack of data on longer-term outcomes, case-mix adjustment, and consideration of the importance of clinical frailty.

The purpose of this study was to assess the epidemiology of frailty in patients subject to RRT review. Specifically, we assessed the frequency and distribution of frailty, before making a comparison of outcomes for patients judged to have high versus low levels of frailty. In addition, we investigated whether frailty was associated with "poor recovery" (death or becoming hospital-dependent) at 30 days, after adjustment for potentially confounding variables.

\section{Methods}

\section{Study design, infrastructure, and coordination}

In this international prospective observational cohort study, centres with existing RRTs were invited to collect data during a 7-day period in February-March 2016. Expressions of interest were initially obtained from sites that contributed to a previous study [4]. The study was also promoted on the websites of the International Society for Rapid Response
Systems (http://rapidresponsesystems.org) and the UK National Outreach Forum (http://www.norf.org.uk).

All patients triggering RRT review at each site during the study period were included. RRTs followed up all patients at $24 \mathrm{~h}$ following their call and at hospital discharge or 30 days following the event trigger (whichever came sooner). RRTs at participating sites collected data using paper-based case report forms for each patient. Sites then anonymised and submitted all data via an encrypted electronic database for central analysis. The management and writing committee, consisting of all authors of the paper, oversaw the study. The committee directed study design, review and promulgation of the study protocol, collation of results, generation of data queries, resolution of data queries with study sites, data analysis, and writing of the manuscript.

\section{Nature of data collected}

Each participating site provided information on the characteristics of their institution and the principal model of their RRT. Each patient was identified using a unique patient identifier, with the patient's identity kept secure and only discoverable locally by the contributing centre. Individual sites kept a master list of subjects and could re-identify patients during the data query process if required. Data were collected on demographics including age, gender, source of admission, parent unit, and date of hospital admission. We recorded the date and time of the RRT call and the resuscitation status of the patient before the RRT call (that is, for full active care, for limited critical care, not for critical care, or do not attempt resuscitation).

Frailty can be defined by a frailty phenotype or accumulation of deficits model to calculate a frailty index [5]. The latter uses accumulation of 70 deficits including functional deficits and chronic diseases as a model of frailty. The clinical frailty scale (CFS) is a clinical derivative designed initially as a screening tool, and correlates highly with the frailty index. Frailty was measured using the CFS (see Appendix) based on information provided by either the patient or family members. This 9-point scale contains categories for severely ill patients added on to Rockwood's original 7-point scale. The latter was evaluated prospectively in a large cohort, where each increment was associated with both higher mortality and a greater need for long-term institutional care at 70 months [6]. In critically ill patients, a cutoff point $\geq 5$ has been associated with shorter-term survival including hospital mortality [1-3]. Given the shorter-term follow up of the present study design, and potential ambiguity in family members' ability to identify early frailty, we therefore compared outcomes of patients attended by the RRT, who had a frailty level $1-4$ versus those with levels $\geq 5$. The lead authors of our study tested this frailty scale along with the other data collection documents on patients in their own institutions 
prior to the study opening. Lead investigators at each site were provided with written information and graphical illustrations of the CFS. Local investigators and members of their respective rapid response teams (RRTs) were responsible for conducting frailty assessments using information available at the time of RRT activation. This included documented evidence from the patient's medical record including history from the patient and/or their relatives and assessments by nursing staff and allied health professionals such as physiotherapists and occupational therapists.

Vital signs, oxygen use, and mental status at the time of arrival of the RRT were recorded, and from these we calculated the UK National Early Warning Score (NEWS) [7] and abbreviated organ failure assessment score (qSOFA), as additional analysis parameters [8]. The time between the call to the RRT and subsequent transfer to ICU was calculated and compared in those patients that were admitted; the analysis used a time greater than $4 \mathrm{~h}$ as a cutoff point for "delayed transfer to the ICU" [9]. The analysis also considered the risks of weekend calls (5.00 p.m. Friday to 6.00 a.m. Monday) and night calls (midnight to 6.00 a.m.).

We also recorded whether the patient was transferred to an ICU or operating room in the following $24 \mathrm{~h}$ and the date and time of such events. If there was a perceived delay, we recorded this as either: "no availability of critical care bed/operating theatre", or that the "patient was initially stable on the ward", there was "requirement for an initial investigation", or "requirement for an initial intervention".

For patients not admitted to an intensive care unit, we verified whether the patient died within $24 \mathrm{~h}$ of the first call and whether the death occurred with a do not attempt resuscitation (DNAR) order in place, whether the initial call trigger resolved, whether new or increased limitations of medical therapy were instituted, and whether there was another RRT call within the next $24 \mathrm{~h}$. For patients who died without a valid DNAR order, we recorded whether cardiopulmonary resuscitation was performed.

\section{Statistical analysis}

Data from individual sites were compiled in a single record with the addition of a country and site code and patient serial numbers. All statistical analyses were performed using SPSS (v.24). The continuous variables are expressed as mean \pm standard deviation (for normally distributed variables) or as median and IQR (for variables that are not normally distributed), and the categorical variables are expressed as numbers (percentages). The patients were divided into two independent groups, namely, frail and nonfrail patients, based on a CFS score of 1-4 or $\geq$ 5 , respectively. For descriptive statistics, the categorical variables were compared between frailty groups using the chi-square test or Fisher's exact test, as appropriate. The continuous variables were compared between frailty groups using the independent samples Student $t$ test (for normally distributed variables) or the Mann-Whitney $U$ test (for variables that are not normally distributed).

Multivariable logistic regression analysis was performed to determine risk factors for the composite endpoint of "poor recovery" (patients who had died or become hospital-dependent) at 30 days; this analysis was also done for the outcomes of mortality at $24 \mathrm{~h}$, mortality at 30 days, and hospital dependence at 30 days. The independent variables were UK as the country, age, male, admitted under a medical specialty, frailty level, patients per nurse, existing limitation of care, National Early Warning Score (NEWS), qSOFA score, weekend calls, and night calls. The model fit was assessed using the Hosmer-Lemeshow test. A two-sided $p$ value $<0.05$ was considered to be statistically significant for all of the comparisons.

Analysis was carried out on the entire patient sample, and subsequently in those who survived 30 days. The latter group was evaluated for non-resolution of illness at the 30-day point; the end point "hospital dependence" was used to define those at that time that remained in the hospital, were transferred to another hospital, or who received skilled nursing or hospice care.

\section{Results \\ Demographics}

The study accrued data in 2016 from 1133 patients from 43 different medical institutions across 8 countries. Three nations contributed more than 100 patients with the overall distribution shown in Table 1A.

\section{Inpatient characteristics}

Patient characterististics are shown in Table 1. Of note, $67 \%$ of patients $(764 / 1133)$ were admitted under medical specialties. Overall, $18 \%$ of patients (208/1133) had existing limitations of care prior to the RRT call. The mean NEWS score at the time of the RRT review was $6.7 \pm 3.2(\mathrm{SD})$.

\section{Outcomes at $\mathbf{2 4} \mathrm{h}$ and care escalation}

Cardiac arrests occurred in $1.4 \%$ of patients (16/1133) undergoing RRT review; all but 1 (15 out of 16) of these patients received cardiopulmonary resuscitation (CPR). Repeat calls occurred in $8 \%$ of all patients (95/1133); call triggers persisted at $24 \mathrm{~h}$ in $22 \%$ of instances $(253 / 1133)$. Death occurred within $24 \mathrm{~h}$ in $72 / 1133$ study patients (6.4\%). After the RRT call, a new limitation in care was implemented in $17 \%$ of patients (188/1133). Overall, $30 \%$ of patients $(339 / 1133)$ were transferred to the ICU within $24 \mathrm{~h}$ of RRT review (see Table 1B).

\section{Frequency and consequences of frailty}

Data on levels of frailty were available for $99 \%$ of patients $(1119 / 1133)$ and $60 \%(672 / 1119)$ were screened as non-frail with frailty scores of $1-4$, and $40 \%$ (447/1119) were screened 
Table 1 Patients seen by rapid response teams: demographics and interventions

\begin{tabular}{|c|c|c|c|c|c|c|}
\hline & Total & UK & Netherlands & Denmark & Australia & Other \\
\hline \multicolumn{7}{|l|}{ A. Demographics } \\
\hline Number of patients & 1133 & 722 & 199 & 124 & 59 & 29 \\
\hline Number of centres & 43 & 23 & 10 & 4 & 2 & 4 \\
\hline Age (years) & $67(18)$ & $67(19)$ & $67(15)$ & $71(13)$ & $64(21)$ & $62(18)$ \\
\hline Male & $581(51 \%)$ & $364(50 \%)$ & $104(52 \%)$ & $70(56 \%)$ & $30(51 \%)$ & $13(45 \%)$ \\
\hline Originally from home & $950(84 \%)$ & $608(84 \%)$ & $179(90 \%)$ & $89(72 \%)$ & $49(83 \%)$ & $24(83 \%)$ \\
\hline Admitted under a medical specialty. & $764(67 \%)$ & $500(69 \%)$ & $123(62 \%)$ & $92(74 \%)$ & $30(51 \%)$ & $19(66 \%)$ \\
\hline Frailty level, percent that were $\geq 5^{\mathrm{a}}$ & $40 \%$ & $41 \%$ & $32 \%$ & $50 \%$ & $29 \%$ & $41 \%$ \\
\hline Patients per nurse, percent at $1-4 / 5-8 / \geq 9$ & $28 / 52 / 20(\%)$ & 20/61/19 (\%) & 29/40/31 (\%) & $47 / 34 / 20(\%)$ & $71 / 25 / 0(\%)$ & $48 / 41 / 10(\%)$ \\
\hline Existing care limitation in place & $208(18 \%)$ & $122(17 \%)$ & $34(17 \%)$ & $35(28 \%)$ & $11(19 \%)$ & $6(21 \%)$ \\
\hline Mean NEWS (SD) & $6.7(3.2)$ & $6.1(3.1)$ & $7.7(3.0)$ & $8.8(302)$ & $6.5(3.3)$ & $6.9(2.8)$ \\
\hline Mean qSOFA (SD) & $1.2(0.8)$ & $1.1(0.8)$ & $1.3(0.8)$ & $1.3(0.8)$ & $1.2(0.8)$ & $1.2(0.7)$ \\
\hline On antibiotics prior to RRT call & $648(57 \%)$ & $440(61 \%)$ & $108(54 \%)$ & $68(55 \%)$ & $18(31 \%)$ & $14(55 \%)$ \\
\hline \multicolumn{7}{|l|}{ B. Interventions } \\
\hline On antibiotics following RRT call & $659(58 \%)$ & $485(67 \%)$ & $119(60 \%)$ & $31(25 \%)$ & $8(14 \%)$ & $14(48 \%)$ \\
\hline Transferred to ICU & $339(30 \%)$ & $151(21 \%)$ & $120(60 \%)$ & $42(34 \%)$ & $15(25 \%)$ & $11(38 \%)$ \\
\hline Mean RRT-ICU time (h) & 9.2 & 12.5 & 3.4 & 6.3 & 24.8 & 13.1 \\
\hline Needed surgical operation & $21(2 \%)$ & $10(1 \%)$ & $6(3 \%)$ & $3(2 \%)$ & $2(3 \%)$ & 0 \\
\hline Full code death & $16(1 \%)$ & $12(2 \%)$ & $1(1 \%)$ & $2(2 \%)$ & $1(2 \%)$ & 0 \\
\hline Received CPR & $15(1 \%)$ & $11(2 \%)$ & $2(1 \%)$ & $1(1 \%)$ & $1(2 \%)$ & 0 \\
\hline Call trigger persisted & $253(22 \%)$ & $145(20 \%)$ & $24(12 \%)$ & $60(48 \%)$ & $17(29 \%)$ & $7(24 \%)$ \\
\hline New limitation in care & $188(17 \%)$ & $136(19 \%)$ & $16(8 \%)$ & $23(19 \%)$ & $9(15 \%)$ & $4(14 \%)$ \\
\hline Repeat RRT call & $95(8 \%)$ & $73(10 \%)$ & $9(5 \%)$ & $8(6 \%)$ & $3(5 \%)$ & $2(7 \%)$ \\
\hline
\end{tabular}

Demographics of study patients are shown in total and according to nation. The final column is the sum of countries contributing less than 25 patients each to the analysis, and includes Mexico (16 patients), Ireland (7 patients), Portugal (5 patients), and the USA (1 patient)

$R R T$ rapid response team, qSOFA quick sequential organ failure assessment, CFS clinical frailty scale, NEWS National Early Warning Score, CPR

cardiopulmonary resuscitation

aFrailty scores were determined using the Dalhousie clinical frailty scale and condensed into two intervals as noted in "Methods"

as frail with scores $\geq 5$. Comparing these two groups, patients screened as frail were more likely to have a higher mean age (74 versus 63 years), admission under a medical specialty, existing limitations of care, higher qSOFA scores, new limitations in care, and poor recovery from illness $(p<0.001$ for all; see Table 2). Patients screened as frail were also more likely to have a higher NEWS score $(p=0.0047$; see Table 2), and higher nurse-to-patient ratio (23\% of frail patients had a patients-per-nurse load of 1-4 vs. $30 \%$ of non-frail patients; $p=0.0048$, see Table 2 ).

ICU admissions were less common in patients in the higher frailty class $(21 \%$ vs. $36 \%, p<0.001)$. In addition, patients with a frailty score $\geq 5$ were more likely to die within $24 \mathrm{~h}(11 \%$ vs. $4 \%, p<0.001)$ and within 30 days of RRT review $(40 \%$ vs. $21 \%, p<0.001)$ compared to those patients with scores of 1-4.

\section{Associations with mortality and hospital dependence at 30 days}

Of the 1133 study patients, 6\% (72) died within $24 \mathrm{~h}$, and $16 \%$ (12) of these deaths were unexpected (died with "full code" status). At 30 days, $29 \%$ of the patients (321) had died and $25 \%$ of the patients (283) were still in the hospital or dependent on skilled nursing (including hospice care; see Table 3).

In the multivariable logistic regression analysis, variables significantly associated with the composite endpoint of poor recovery (died or hospital-dependent at 30 days) were age (OR,1.04; 95\% CI, 1.03-1.05; $p<0.001)$, existing limitation of care (OR, 2.0; 95\% CI, 1.3-3,0; $p<0.001)$, and qSOFA score $(p<0.001)$. Compared to patients considered very fit and well by the frailty scale (levels 1 and 2), each two-step increase in frailty had a near doubling of risk of mortality or dependence on formal care services at 30 days (OR range 2.9-9.9; see Table 4).

\section{Discussion}

\section{Summary of major findings}

We conducted a prospective observational study amongst 43 hospitals in 8 countries involving 1133 patients triggering RRT review, to assess the frequency and impact of clinical frailty in this patient group. Key clinical outcomes at both 
Table 2 Presence and impact of frailty in patients seen by rapid response teams

\begin{tabular}{|c|c|c|c|}
\hline Variable & Frailty level 1-4 & Frailty level $\geq 5$ & $p$ value \\
\hline Count & $n=672(60 \%)$ & $n=447(40 \%)$ & \\
\hline Age (years) & $63(18)$ & $74(15)$ & $p<0.001$ \\
\hline Male & $263(54 \%)$ & $215(48 \%)$ & $p=0.051$ \\
\hline On a medical service & $390(58 \%)$ & $335(75 \%)$ & $p<0.001^{b}$ \\
\hline \multicolumn{4}{|l|}{ Patients per nurse } \\
\hline $1-4$ & $203(30 \%)$ & $101(23 \%)$ & $p=0.0048^{\mathrm{b}}$ \\
\hline $5-8$ & $330(50 \%)$ & $248(55 \%)$ & $p=0.031^{b}$ \\
\hline $9-12$ & $103(15 \%)$ & $69(15 \%)$ & $p=1.0$ \\
\hline $13-17$ & $27(5 \%)$ & $20(5 \%)$ & $p=0.716$ \\
\hline$>17$ & 0 & 3 & $P=0.060$ \\
\hline Existing limitation in care & $54(8 \%)$ & $156(35 \%)$ & $p<0.001^{b}$ \\
\hline Resolution of trigger & $296(44 \%)$ & $192(43 \%)$ & $p=0.950$ \\
\hline Repeat MET call & $54(8 \%)$ & $40(9 \%)$ & $p=0.440$ \\
\hline Median NEWS (IQR) & $6(4-9)$ & $7(5-9)$ & $p=0.0047^{\mathrm{a}}$ \\
\hline Mean qSOFA score (SD) & $1.1(.78)$ & $1.4(.82)$ & $p<0.001^{\mathrm{a}}$ \\
\hline On antibiotics following MET call & $383(57 \%)$ & $273(61 \%)$ & $p=0.216$ \\
\hline Antibiotics before MET call & $370(55 \%)$ & $273(61 \%)$ & $p=0.081$ \\
\hline ICU admission & $242(36 \%)$ & $94(21 \%)$ & $p<0.001^{\mathrm{b}}$ \\
\hline Mean MET to ICU interval (h) & 10.0 & 6.7 & $p=0.701$ \\
\hline MET- > ICU less than $4 \mathrm{~h}$. & $181(27 \%)$ & $125(28 \%)$ & $p=0.892$ \\
\hline Died within $24 \mathrm{~h}$ of MET call & $24(4 \%)$ & $48(11 \%)$ & $p<0.001^{b}$ \\
\hline Full code status at time of death & $5(0.7 \%)$ & $8(1.8 \%)$ & $p=0.153$ \\
\hline Received CPR & $6(0.9 \%)$ & $9(2.0 \%)$ & $p=0.119$ \\
\hline New limitation in care & $74(11 \%)$ & $116(26 \%)$ & $p<0.001^{b}$ \\
\hline Died within 30 days & $144(21 \%)$ & $177(40 \%)$ & $p<0.001^{b}$ \\
\hline If alive, hospital-dependent at 30 days & $139(26 \%)$ & $144(32 \%)$ & $p<0.001^{b}$ \\
\hline Died or hospital-dependent at 30 days & $283(42 \%)$ & $321(72 \%)$ & $p<0.001^{b}$ \\
\hline
\end{tabular}

Patients seen by rapid response teams were assessed by the Dalhousie clinical frailty scale and analysed according to scores of 1-4 and $\geq 5 ; 14$ of the 1133 patients in this study had missing frailty data and 15 had missing data on the nurse-to-patient ratio

MET Medical emergency team, qSOFA quick sequential organ failure assessment, NEWS National Early Warning Score, CPR cardiopulmonary resuscitation

${ }^{a}$ Mann-Whitney $U$ test

${ }^{\mathrm{b}}$ Fisher's exact test

$24 \mathrm{~h}$ and 30 days are summarised in Fig. 1. We found that two fifths of patients were screened as frail - a characteristic that was associated with older age, admission under a medical specialty, increased severity of illness at the time of the RRT, and substantially, limitations of care including
ICU admission. Importantly, $72 \%$ of patients who were screened as frail at the time of clinical deterioration were either dead or dependent on hospital care at 30 days. Even after adjustment for potential confounders such as age and acuity of illness, frailty remained independently associated

Table 3 Association between frailty levels and clinical end points

\begin{tabular}{llllll}
\hline CFS & Total & Died within $24 \mathrm{~h}$ & Died within 30 days & Hospital-dependent at 30 days & Poor recovery \\
\hline $1-2$ & 312 & $6(2 \%)$ & $41(13 \%)$ & $49(16 \%)$ & $90(29 \%)$ \\
$3-4$ & 360 & $18(5 \%)$ & $103(29 \%)$ & $90(25 \%)$ & $193(54 \%)$ \\
$5-6$ & 287 & $29(10 \%)$ & $113(39 \%)$ & $80(28 \%)$ & $193(67 \%)$ \\
$7-9$ & 160 & $19(12 \%)$ & $64(40 \%)$ & $64(40 \%)$ & $128(80 \%)$ \\
& 1119 & 72 & 321 & 283 & 604 \\
\hline
\end{tabular}

Clinical end points evaluated are shown as well as their distribution amongst two-step intervals of the clinical frailty scale (CFS). "Poor recovery" is a composite endpoint indicating either hospital dependence or mortality at 30 days 
Table 4 Univariable and multivariable logistic regression analysis for "poor recovery"

\begin{tabular}{|c|c|c|c|c|c|c|}
\hline \multirow[t]{2}{*}{ Variable } & \multicolumn{3}{|l|}{ Univariable } & \multicolumn{3}{|c|}{ Multivariable } \\
\hline & $\mathrm{OR}$ & $95 \% \mathrm{Cl}$ & $p$ value & $\mathrm{OR}$ & $95 \% \mathrm{Cl}$ & $p$ value \\
\hline UK country & 0.8 & $0.6-1.0$ & 0.057 & 0.8 & $0.6-1.1$ & 0.151 \\
\hline Age & 1.0 & $1.0-1.1$ & $<0.001$ & 1.04 & $1.03-1.05$ & $<0.001$ \\
\hline Male & 1.1 & $0.8-1.4$ & 0.548 & & & \\
\hline Medical admission & 1.4 & $1.1-1.8$ & 0.013 & & & \\
\hline Frailty level $^{\mathrm{a}}$ & & & & & & $<0.001$ \\
\hline $1-2$ & Reference & & & Reference & & \\
\hline $3-4$ & 2.9 & $2.1-3.9$ & $<0.001$ & 1.8 & $1.2-2.5$ & $<0.001$ \\
\hline $5-6$ & 5.1 & $3.6-7.2$ & $<0.001$ & 2.2 & $1.5-3.4$ & $<0.001$ \\
\hline $7-9$ & 9.9 & $6.2-16.6$ & $<0.001$ & 5.1 & $3.1-8.6$ & $<0.001$ \\
\hline \multicolumn{7}{|l|}{ Patients per nurse $\mathrm{e}^{\mathrm{b}}$} \\
\hline $1-4$ & Reference & & & & & \\
\hline $5-8$ & 1.3 & $1.0-1.7$ & 0.065 & & & \\
\hline $9-12$ & 1.3 & $0.9-1.9$ & 0.142 & & & \\
\hline$\geq 13$ & 1.3 & $0.7-2.4$ & 0.384 & & & \\
\hline Existing limitation of care & 4.5 & $3.1-6.4$ & $<0.001$ & 2.0 & $1.3-3.0$ & $<0.001$ \\
\hline NEWS & 1.1 & $1.0-1.1$ & $<0.001$ & & & \\
\hline qSOFA score & 1.8 & $1.5-2.1$ & $<0.001$ & & & $<0.001$ \\
\hline 1 & & & & 1.7 & $1.1-2.4$ & 0.009 \\
\hline 2 & & & & 2.4 & $1.6-3.7$ & $<0.001$ \\
\hline 3 & & & & 4.3 & $2.1-9.1$ & $<0.001$ \\
\hline Weekend calls & 1.0 & $0.8-1.3$ & 0.861 & & & \\
\hline Night calls & 0.8 & $0.6-1.1$ & 0.104 & 0.7 & $0.5-1.0$ & 0.065 \\
\hline
\end{tabular}

Univariable and multivariable analysis for "poor recovery". The Hosmer-Lemeshow test suggested a good fit ( $p=0.29)$

qSOFA quick sequential organ failure assessment, NEWS National Early Warning Score

${ }^{\text {a }}$ Frailty levels were compared for the proportion with 1-2 versus higher levels

${ }^{b}$ Nursing ratios were compared for the proportion with 1-4 patients per nurse versus higher loads

The RRT call: an indicator of serious deteriorations

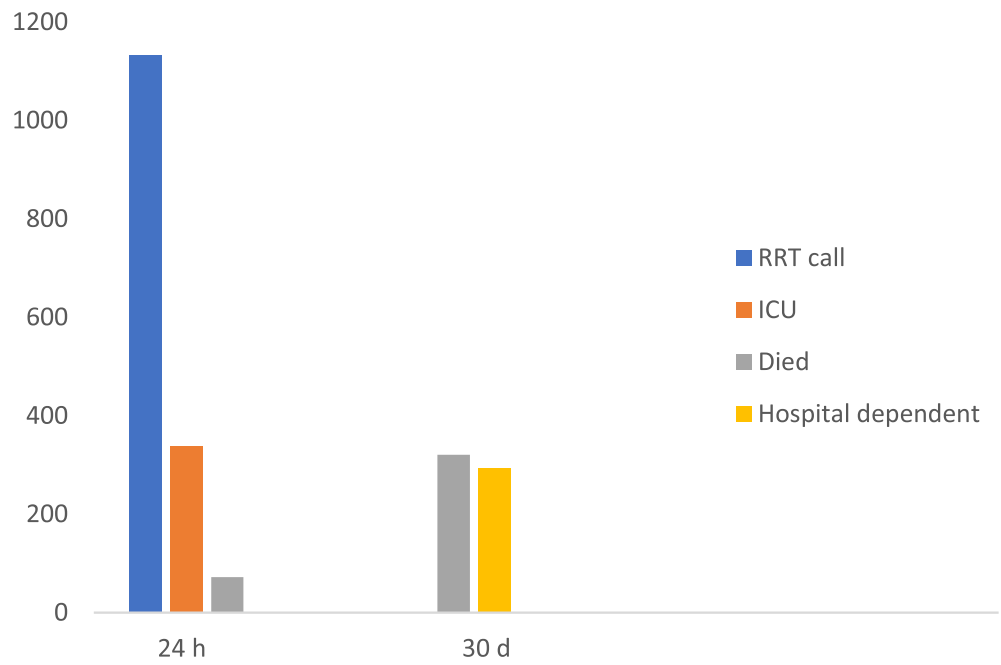

Fig. 1 Key patient outcomes during the first 24-h of an emergency team call and 30-day outcomes are presented. RRT, rapid response team 
with 30-day "poor recovery". Figure 2 is a graphic demonstration of this result.

\section{Comparison with previous studies}

To our knowledge, this is the first study to prospectively investigate clinical frailty in patients with significant deterioration on general wards and reviewed by the RRT. Several studies have examined the epidemiology of frailty in patients undergoing elective surgery and found it to be associated with an increased risk of post-operative adverse events $[10,11]$. Similar to the findings of the present study, others have identified greater short-term mortality in patients with limitations of medical treatment at the time of an RRT call [12-14].

In this study, we were able to assess mortality and dependence on care services at 30 days. Hall and colleagues have recently also shown clinical frailty to be associated with increased 30-day mortality for patients undergoing elective surgery [15]. They used a clinical frailty score in order to assist clinicians in the planning and delivery of perioperative care for frail patients, with subsequent reductions in mortality. In patients with acute hospital admissions due to heart failure, a retrospective cohort study found the incidence of frailty to be $36 \%$ and independently associated with mortality at 30 days [16]. These data are consistent with our findings, however, our cohort captured patients from both medical and surgical specialities, with a preponderance of higher frailty scores in elderly patients admitted under medical specialities.

\section{Study strengths and weakness}

Our study is the first to prospectively assess frailty in patients subject to RRT review. It is a prospective multi- national study, utilising standardised and previously validated data collection tools. Efforts to develop models of frailty in acute care have previously relied on large historical datasets for validation [17]. We have shown the feasibility of performing an objective frailty assessment at the time of acute care, and the biologic plausibility of the results. Refinement of this and other measures of trajectory and response to intensive care is a key research priority.

Despite our study's strengths, many hospitals and countries contributed relatively small numbers of patients, and two thirds of data came from the UK. This potentially limits the international generalizability of our findings. Although we tested the frailty assessment tool at lead sites prior to the study commencing, we were not able to provide specific training for investigators prior to them performing patient frailty assessments at their institution; however, patient interpretation of the questions and their significance is likely to produce more variability than clinicians. Finally, a limitation of the study was the lack of data on comorbidities and admission diagnosis. Nonetheless, our results demonstrate that clinicians can make a clinical bedside assessment that is associated with patient outcome, and one that probably warrants inclusion into discussions about the goals and expectations of care. These discussions might be challenging in clinical practice, because of the lack of reliable predictors and partially because of the lack of training.

\section{Areas for future research}

Bedside assessment of frailty may be feasible and associated with short-term outcomes, but there is a need to assess longer-term mortality and functional recovery in patients subject to RRT review and whether the high attributable

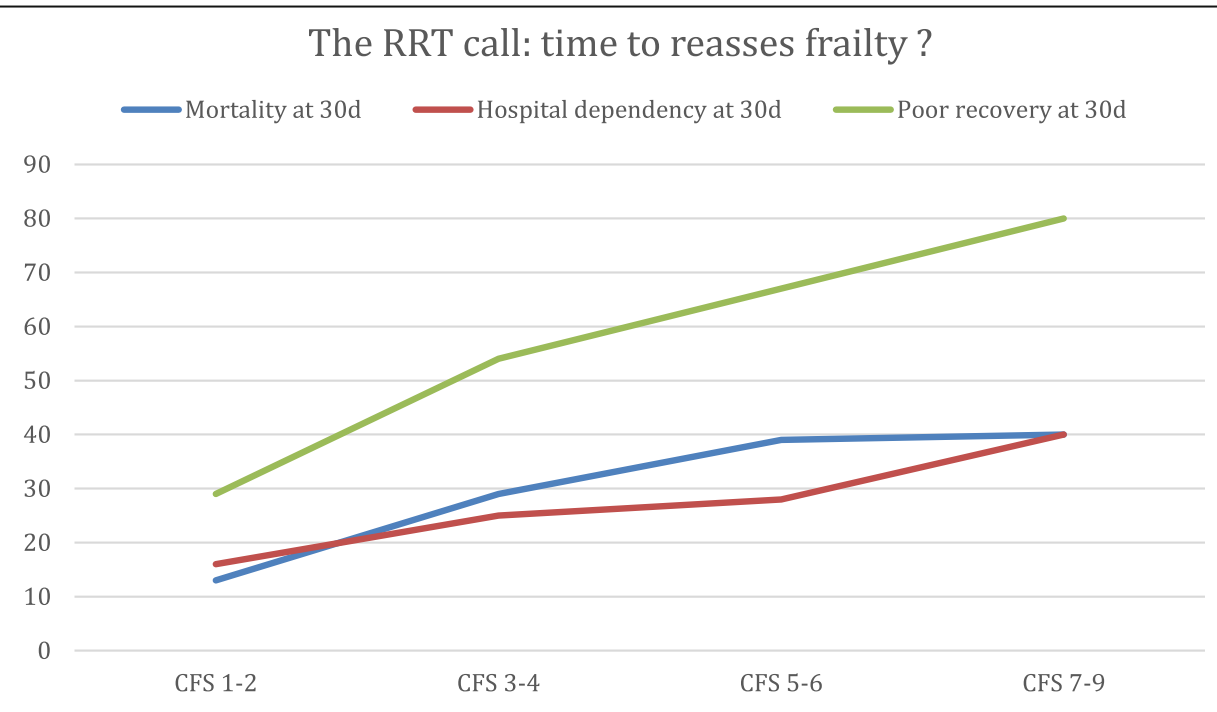

Fig. 2 The impact of clincal frailty on 30-day outcomes is presented. The numbers on the horizontal axis indicate the ordinal values of the Dalhousie clinical frailty scale (CFS) (see "Methods"). The vertical axis indicates the percentage of patients in each category. Poor recovery is a composite measure of both mortality and hospital dependence at 30 days. RRT, rapid response team; d, days 
mortality in these patients is at all preventable. There is also a need to better understand the interaction between frailty and clinical deterioration both in the context of acute physiology and the context of team behaviour and to explore possibilities of using frailty scores to enhance advanced care planning and end of life care.

\section{Conclusions}

Our findings show it is feasible to assess clinical frailty in ward patients experiencing clinical deterioration subject to RRT review. Moreover, we found that frailty is associated with mortality and dependence on hospital care at 30 days amongst general ward patients.

Currently, the RRT is confronted with issues around end of life care and limiting of medical treatment in one third of all RRT calls [13] and the strong association between limitations of care and frailty suggests that there is both subjective and objective evidence that a complete recovery from illness may not be possible. Our results demonstrate that clinicians can make a clinical bedside assessment that is associated with patient outcome, and one that probably warrants inclusion into discussions about the goals and expectations of care.

We believe that using the clinical frailty scale presents an opportunity to improve advance care planning and end of life care discussions in patients subject to a RRT review. Moreover, we speculate that using the clinical frailty scale early on admission to the general ward, provided that it is implemented with dedicated and adequate training and support, one can identify (previously unrecognized) frail patients and improve the dialogue between the provider and patient and family on the expected course of recovery and/ or survivorship expectations, leading to a clear person-centered high-value treatment plan.

\section{Appendix}

The Canadian Study of Health and Aging Clinical Frailty Scale

1. Very fit - robust, active, energetic, well-motivated and fit; these people commonly exercise regularly and are amongst the fittest for their age.

2. Well - without active disease, but less fit than people in category 1 . Active occasionally.

3. Managing well- people whose medical problems are well controlled, but are not regularly active beyond routine walking.

4. Vulnerable - although not frankly dependent, these people commonly complain of being "slowed up" or have disease symptoms limiting activity

5. Mildly frail - more evident slowing and need help with high order ADLs (finance, transportation). Progressive impairment in shopping and walking outside alone or in doing housework.
6. Moderately frail - help is needed with all outside activities and with keeping house inside. May need help with stairs, bathing, and assistance with dressing.

7. Severely frail - completely dependent on others for personal care-either from physical or cognitive disability. May seem stable and not at high risk of dying.

8. Very severely frail - completely dependent, approaching end of life. Not likely to recover from even a minor illness

9. Terminally ill - approaching end of life. Life expectancy $<6$ months who are not otherwise evidently frail.

Adapted from Rockwood et al. [5] and from Clinical Frailty Scale Version 1.2. c. 2007-2009; Geriatric Medicine Research, Dalhousie University, Halifax, NS, Canada. http:// geriatricresearch.medicine.dal.ca/clinical_frailty_scale.htm. Accessed 1/12/2016.

\section{Abbreviations}

CFS: Clinical frailty scale; CPR: Cardiopulmonary resuscitation; DNAR: Do not attempt resuscitation; MET: Medical Emergency Team; METHOD group: Medical Emergency Team Hospital Outcomes after a Day group; NEWS: National Early Warning Score; qSOFA: Quick sequential (sepsisrelated) organ failure assessment; RRT: Rapid response team (includes Medical Emergency Team or Critical Care Outreach Team and denotes individuals or groups of healthcare professionals responding to deterioration hospitalised patients in locations other intensive care)

\section{Acknowledgements}

Special thanks to the International Society for Rapid Response Systems (iSRRS) and the UK National Outreach Forum (NOrF) for their support and assistance in recruiting site investigators.

The Medical Emergency Teams Hospital Outcomes in a Day (METHOD) group site investigators: (alphabetically by institution, all in the UK unless otherwise specified as Australia (AUS), Denmark (DNK), Mexico (Mx), Portugal (P), The Netherlands (NL) or Ireland (Ire)): Addenbrooke's Hospital, Cambridge - M Trivedi. Albert Schweitzer Hospital, Dordrecht, NL - H Ponssen \& R So. Antonius Ziekenhuis, Sneek, NL - K Koster. Basildon and Thurrock University Hospital, Basildon - S Smit. Central Manchester University Hospitals, Manchester - S Michail, S Tunstall, E Davies and J Bannard-Smith. East Surrey Hospital, Redhill - C Rowley. Elisabeth TweeSteden Ziekenhuis/locatie Noord, Tilburg, NL - M Verheijen. Glan Clwyd Hospital, Bodelwyddan, Wales - C Chalmers. Hospital Angeles Pedregal, Mexico City, Mx - A Elguea. Hospital of Nykobing F., Nykobing F., DNK - R Ulka. Hospital Santo Antonio, Porto, P - AR Silva. Jeroen Bosch Ziekenhuis, 's Hertogenbosch, NL - T van Zuylen and P de Jager. Maidstone \& Tunbridge Wells, Maidstone - J Lennon. Maxima Medisch Centrum, Veldhoven, NL A de Gooijer. Medway NHS Foundation Trust, Gillingham - C Plowright. Morriston Hospital, Swansea, Wales - C Battle. Noord West Ziekenhuisgroep, Alkmaar, NL - D Sep. North Zealand Hospital, Hillerød, DNK - AM Kodal. Prince Charles Hospital, Merthyr Tydfil, Wales - V Jones. Princess Royal Hospital, Haywards Heath - K Kemsley. Radboud University Medical Centre, Nijmegen, NL - R Verhage, E Brull. Reinier de Graaf Gasthuis, Delft, NL - T van Zon, P Tangkau. Royal Berkshire NHS Foundation Trust, Reading - M Wilson. Royal Glamorgan Hospital, Pontyclum, Wales - J Burke. Royal London Hospital, London - A Hurding. Royal Melbourne Hospital, Melbourne, AUS - A Jordan. Royal Sussex County Hospital, Brighton - K Kemsley. Rijnstate Hospital, Arnhem, NL - J van Vliet. Slagelse Hospital, Slagelse, DNK - S Iverson. Stoke Mandeville Hospital, Aylesbury - J Philips. Sunderland Royal Hospital, Sunderland - R Duncan. Tallaght Hospital, Dublin, Ire - M Donnelly. University Hospital Southampton, Southampton - K Edwards. VieCuri Medical Centre, Venlo, NL - DJ Mehagnoul. Watford General Hospital, Watford - P Hart. Wollongong Hospital, Wollongong, Aus - L Collins. Wrexham Maelor Hospital, Wrexham, Wales - H Reddy. 
Yeovil District Hospital, Yeovil - E Young. Ysbyty Gwynedd, Bangor, Wales - C Subbe.

\section{Availability of data and materials}

The datasets used and/ or analysed during the current study are available from the corresponding author on reasonable request.

\section{Authors' contributions}

The METHOD group consists of the following: Organising and writing committee: JB, DJ, GL, RS, CS. Inception of the study hypotheses and design: CS. Data collection and handling from participating sites: JB. Data analysis: GL, JR. All authors read and approved the final manuscript.

\section{Ethics approval and consent to participate}

The study protocol was reviewed by the internal review panel of the Betsi Cadwaladr University Health Board. In view of the study's observational nature and the fact that all data were to be de-identified, the Health Board waived the need for formal ethics review or individual patient consent (Research Ethics Committee (REC) reference 16/WAV026). All participating sites were asked to register the study with their respective audit departments and to comply with their local data protection policies when handling study data. Collaborators consented to the statement that "Health Research Ethics Committee (HREC) approval has been obtained or need for HREC approval been waived locally." All ethics committees approached gave their approval.

\section{Consent for publication}

None applicable.

\section{Competing interests}

The authors declare that they have no competing interests.

\section{Publisher's Note}

Springer Nature remains neutral with regard to jurisdictional claims in published maps and institutional affiliations.

\begin{abstract}
Author details
${ }^{1}$ Department of Intensive Care, Albert Schweitzer Hospital, Albert Schweitzerplaats 25, Dordrecht, the Netherlands. ${ }^{2}$ Department of Critical Care, Manchester Royal Infirmary, Central Manchester University NHS Hospitals, Manchester Academic Health Science Centre, Manchester M13 9WL, UK. ${ }^{3}$ Acute, Respiratory \& Critical Care Medicine, Ysbyty Gwynedd, Bangor, UK. ${ }^{4}$ Department of Intensive Care, Austin Hospital, 145 Studley Rd, Heidelberg, VIC, Australia. ${ }^{5}$ Department of Biostatistics, Erasmus Medical Centre, Rotterdam, the Netherlands. ${ }^{6}$ Department of Anesthesia, Stanford University School of Medicine, 300 Pasteur Dr. H3580, Stanford, CA 94305, USA.
\end{abstract}

Received: 26 December 2017 Accepted: 27 July 2018

Published online: 22 September 2018

\section{References}

1. Brummel NE, Bell SP, Girard TD, Pandharipande PP, Jackson JC, Morandi A, Thompson JL, Chandrasekhar R, Bernard GR, Dittus RS, Gill TM, Ely EW. Frailty and subsequent disability and mortality among patients with critical illness. Am J Respir Crit Care Med. 2017:196(1):64-72.

2. Bagshaw SM, Stelfox HT, McDermid RC, Rolfson DB, Tsuyuki RT, Baig N, Artiuch B, Ibrahim Q, Stollery DE, Rokosh E, Majumdar SR. Association between frailty and short- and long-term outcomes among critically ill patients: a multicentre prospective cohort study. CMAJ. 2014;186(2):E95-102.

3. Le Maquet P, Roquilly A, Lasocki S, Asehnoune K, Carise E, Saint Martin M, Mimoz O, Le Gac G, Somme D, Cattenoz C, Feuillet F, Malledant Y, Sequin P. Prevalence and impact of frailty on mortality in elderly ICU patients: a prospective, multicenter, observational study. Intensive Care Med. 2014; 40(5):674-82.

4. Bannard-Smith J, Lighthall GK, Subbe CP, Durham L, Welch J, Bellomo R, Jones DA. Clinical outcomes of patients seen by rapid response teams: a template for benchmarking international teams. Resuscitation. 2016;107:7-12.

5. Searle SD, Mitnitski A, Gahbauer EA, Gill TM, Rockwood K. A standard procedure for creating a frailty index. BMC Geriatr. 2008;8:24.
6. Rockwood K, Song X, MacKnight C, Bergman H, Hogan DB, McDowell I, Mitnitski A. A global clinical measure of fitness and frailty in elderly patients. CMAJ. 2005;173(5):489-95.

7. Royal College of Physicians. National Early Warning Score (NEWS): standardizing the assessment of acute illness severity in the NHS. Report of a working party. London: RCP; 2012.

8. Singer M, Deutschman CS, Seymour CW, Shankar-Hari M, Annane D, Bauer M, Bellomo R, Bernard GR, Chiche JD, Coopersmith CM, Hotchkiss RS, Levy MM, Marshall JC, Martin GS, Opal SM, Rubenfeld GD, van der Poll T, Vincent $J \mathrm{~L}$, Angus DC. The third international consensus definitions for sepsis and septic shock (Sepsis-3). JAMA. 2016;315(8):801-10.

9. Oglesby KJ, Durham L, Welch J, Subbe CP. Score to door time, a benchmarking tool for rapid response system: a pilot multi-centre service evaluation. Crit Care. 2011;15:R180.

10. Partridge JSL, Harari D, Dhesi JK. Frailty in the older surgical patient: a review. Age Ageing. 2012;41:142-7.

11. Makary MA, Segev DL, Pronovost PJ, Syin D, Bandeen-Roche K, Patel P, Syin D, Takenaga R, Devgan L, Holzmueller CG, Tian J, Fried LP. Frailty as a predictor of surgical outcomes in older patients. J Am Coll Surg. 2010;210:901-8.

12. Calzavacca P, Licari E, Tee A, Mercer I, Haase M, Haase-Fielitz A, Jones D, Gutteridge G, Bellomo R. Features and outcome of patients receiving multiple medical emergency team reviews. Resuscitation. 2010;81(11):1509-15.

13. Jones DA, Bagshaw SM, Barrett J, Bellomo R, Bhatia G, Bucknall TK, Casamento AJ, Duke GJ, Gibney N, Hart GK, Hillman KM, Jäderling G, Parmar A Parr MJ. The role of the medical emergency team in end-of-life care: a multicenter, prospective, observational study. Crit Care Med. 2012:40(1):98-103.

14. Jones D, Moran J, Winters B, Welch J. The rapid response system and endof-life care. Curr Opin Crit Care. 2013;19(6):616-23.

15. Hall DE, Arya S, Schmid KK, Carlson MA, Lavedan P, Bailey TL, Purviance G, Bockman T, Lynch TG, Johanning JM. Association od a frailty screening initiative with postoperative survival at 30, 180 and 365 days. JAMA Surg. 2017;152(3):233-40. https://doi.org/10.1001/jamasurg.2016.4219.

16. Martin-Sanchez FJ, Rodriquez-Adrada E, Mueller C, Vidan MT, Christ M, Peacock WF, Rizzi MA, Alquezar A, Pinera P, Lazaro Aragues P, Llorens P, Herrero P, Jacob J, Fernandez C, Miro O. The effect of frailty on 30-day mortality risk in older patients with acute heart failure attended in the emergency department. Acad Emerg Med. 2017;24(3):298-307. https://doi. org/10.1111/acem.13124.

17. Soong J, Poots AJ, Scott S, Donald K, Bell D. Developing and validating a risk prediction model for acute care based on frailty syndromes. BMJ Open. 2015;5(10):e008457. https://doi.org/10.1136/bmjopen-2015-008457.

Ready to submit your research? Choose BMC and benefit from:

- fast, convenient online submission

- thorough peer review by experienced researchers in your field

- rapid publication on acceptance

- support for research data, including large and complex data types

- gold Open Access which fosters wider collaboration and increased citations

- maximum visibility for your research: over $100 \mathrm{M}$ website views per year

At $\mathrm{BMC}$, research is always in progress.

Learn more biomedcentral.com/submissions 